\title{
Proteasomal-Dependent Aggregate Reversal and Absence of Cell Death in a Conditional Mouse Model of Huntington's Disease
}

\author{
Ester Martín-Aparicio, ${ }^{1}$ Ai Yamamoto, ${ }^{2}$ Félix Hernández, ${ }^{1}$ René Hen, ${ }^{2}$ Jesús Avila, ${ }^{1}$ and José J. Lucas ${ }^{1}$ \\ ${ }^{1}$ Centro de Biología Molecular "Severo Ochoa," Consejo Superior de Investigaciones Científicas-Universidad Autónoma \\ de Madrid, 28049 Madrid, Spain, and '2Center for Neurobiology and Behavior, Columbia University, New York, \\ New York 10032
}

\begin{abstract}
Neuronal intranuclear inclusions are a histopathological hallmark of Huntington's disease. Nevertheless, the precise mechanism by which they are formed and their relevance to neuronal cell death and/or dysfunction remains unclear. We recently generated a conditional mouse model of Huntington's disease (HD94) in which silencing expression of mutated huntingtin led to the disappearance of intranuclear aggregates and amelioration of the behavioral phenotype. Here, we analyze primary striatal neuronal cultures from HD94 mice to explore the dynamics of aggregate formation and reversal, the possible mechanisms involved, and the correlation between aggregates and neuronal death. In parallel, we examine symptomatic adult HD94 mice in similar studies and explored the relationship between aggregate clearance and behavioral reversal. We report that, in culture, aggregate formation and reversal were rapid processes, such that $2 \mathrm{~d}$ of transgene expression led to
\end{abstract}

aggregate formation, and $5 \mathrm{~d}$ of transgene suppression led to aggregate disappearance. In mice, full reversal of aggregates and intranuclear mutant huntingtin was more rapid than reported previously and preceded the motor recovery by several weeks. Furthermore, the proteasome inhibitor lactacystin inhibited the aggregate clearance observed in culture, thus indicating that aggregate formation is a balance between the rate of huntingtin synthesis and its degradation by the proteasome. Finally, neither expression of the mutant huntingtin nor aggregates compromised the viability of HD94 cultures. This correlated with the lack of cell death in symptomatic HD94 mice, thus demonstrating that neuronal dysfunction, and not cell loss, triggered by mutant huntingtin underlies symptomatology.

Key words: Huntington's disease; aggregates; conditional transgenic mouse model; fast reversal; proteasome; absence of cell death
Huntington's disease (HD) is a progressive, autosomal dominant, neurodegenerative disorder (Wexler et al., 1987). Patients suffer from motor dysf unction, cognitive decline, and psychological disturbances over 10-15 years until death (Ambrose et al., 1994). The neuropathology is extremely restricted, with atrophy occurring in the striatum and to a lesser extent in the cortex.

The mutation leading to HD is an expansion of CAG repeats near the 5' end of the IT15 gene (The Huntington's Disease Collaborative Research Group, 1993; Rubinsztein et al., 1994; Gusella and MacDonald, 1996). Although unaffected individuals have 35 or fewer repeats, repeat lengths of $>40$ invariably lead to HD. The repeat sequence is translated into a polyglutamine stretch (polyQ) near the $\mathrm{N}$ terminus of the IT15 gene product huntingtin (htt). Eight other autosomal dominant neurological diseases are also caused by a polyQ expansion mutation in their

Received July 2, 2001; revised Aug. 23, 2001; accepted Sept. 5, 2001.

This work was supported by grants from Asociación Española de Corea de Huntington (ACHE), by the United States-Spain Commission for Scientific and Technological Cooperation, by the Hereditary Disease Foundation (HDF), and by an institutional grant from Fundación Ramón Areces. E.M.-A. and A.Y. are recipients of predoctoral fellowships from ACHE and Fundación Ferrer and from HDF, respectively. We thank Drs. Javier Díaz-Nido, Francisco Wandosell, Mar Pérez, and José González-Castaño for helpful discussion and comments; Drs. Eric Kandel and Mark Mayford for the use of the CaMKII $\alpha$-tTA mice; Drs. Erich E. Wanker and Xiao-Jiang Li for kindly providing CAG53b and EM48 antibodies, respectively; Drs. Victoria Arango and Mark Underwood for stereology; and Dr. Ginés Morata for microscope and photography facility. We are also grateful to Carlos Sánchez, Raquel Cuadros, Helena Garuti, and Elena Langa for technical assistance.

Correspondence should be addressed to José J. Lucas, Centro de Biología Molecular "Severo Ochoa," Consejo Superior de Investigaciones Científicas-Universidad Autónoma de Madrid, Facultad Ciencias, Universidad Autónoma de Madrid, Cantoblanco, 28049 Madrid, Spain. E-mail: jjlucas@cbm.uam.es.

Copyright (C) 2001 Society for Neuroscience $0270-6474 / 01 / 218772-10 \$ 15.00 / 0$ respective proteins. These triplet-repeat disorders share an interesting commonality: the presence of intraneuronal aggregates (Ross, 1997; Nakamura et al., 2001).

The relevance of aggregate formation to the etiology of HD is unclear. Aggregates have been implicated as the trigger for neurodegeneration, because both aggregates and pathogenicity are caused by the same polyQ length threshold (Scherzinger et al., 1997). Furthermore, in a transgenic mouse model, these aggregates precede the onset of symptomatology (Davies et al., 1997). Inclusions are also a feature in other non-polyQ disorders, such as Alzheimer's disease and Parkinson's disease, thus suggesting that protein aggregation might cause neurodegeneration through a general mechanism (Price et al., 1998; Tobin and Signer, 2000). Moreover, proteins prone to aggregate, such as mutated huntingtin and cystic fibrosis proteins, have been reported to inhibit the ubiquitin proteasome system (UPS) (Bence et al., 2001). This inhibition in turn altered the half-life of proteins involved in apoptosis and cell survival (Jana et al., 2001). Nevertheless, whereas some studies using transfected cells support aggregateinduced toxicity (Waelter et al., 2001), others dissociate inclusion formation and cell survival (Kim et al., 1999) and even suggest that intranuclear inclusions may reflect a protective mechanism against soluble htt-induced toxicity (Saudou et al., 1998).

Using a conditional animal model of HD that reversibly expressed a mutated htt fragment selectively in the forebrain (HD94) (Yamamoto et al., 2000), we found that abolishing transgene expression in symptomatic mice leads to amelioration of the behavioral phenotype and disappearance of inclusions. This demonstrated that inclusions are dynamic structures and that a con- 
tinuous influx of the protein is required for disease progression. In this initial characterization, however, the minimum time the cell required to clear the aggregates versus the time the organism required to recover its motor behavior was not established, thus hindering the search for possible mechanisms that underlie the recovery process. In light of this, we have established primary neuronal cultures from HD94 mice. With this system, we explore the dynamics of aggregate formation and reversal, the mechanism responsible for reversal, and the correlation between aggregate formation and cell death. As we gained more insight from the culture system, we then returned to the animal model and reexamined the issues sought in vitro.

\section{MATERIALS AND METHODS}

\section{Animals}

HD94 mice were generated as described previously (Yamamoto et al., 2000). Mice were bred at the Centro de Biología Molecular "Severo Ochoa" (Madrid, Spain) and Center for Neurobiology and Behavior (Columbia, NY). Four to five mice were housed per cage, with food and water available ad libitum. Mice were maintained in a temperaturecontrolled environment on a $12 \mathrm{hr}$ light/dark cycle, with light onset at 7:00 A.M.

\section{Primary culture}

Primary cultures of neurons and glia were prepared according to modifications of established procedures (Huettner and Baughman, 1986; Dubinsky, 1989). Pups were killed at postnatal day 1, and tail tissue samples were taken for ulterior genotyping by PCR. Striatal tissue was then dissected and dissociated individually from each pup with the Papain Dissociation System (Worthington, Freehold, NJ). The rest of brain tissue was maintained in 5-bromo-4-chloro-3-indolyl- $\beta$-Dgalactopyranoside (X-gal) solution (see below) to reveal pups of the HD94 genotype. Striatal neurons were maintained in Neurobasal medium (Life Technologies, Gaithersburg, MD) supplemented with 1\% B-27, $5 \%$ fetal calf serum, $0.5 \mathrm{~mm}$ glutamine, $100 \mathrm{U} / \mathrm{ml}$ penicillin, and 100 $\mathrm{mg} / \mathrm{ml}$ streptomycin, and grown on $3 \mu \mathrm{g} / \mathrm{ml}$ laminin (Sigma, St. Louis, $\mathrm{MO})$ and $10 \mu \mathrm{g} / \mathrm{ml}$ poly-L-lysine-coated cell culture chamber slides (Nunc, Naperville, IL). The cells were incubated in $95 \%$ air- $5 \% \mathrm{CO}_{2}$ in a humidified incubator at $37^{\circ} \mathrm{C}$. For inhibition of proteasome activity, neuronal cultures were adjusted to $400 \mathrm{nM}$ or $1 \mu \mathrm{M}$ lactacystin (Calbiochem, La Jolla, CA) and incubated for an additional $48 \mathrm{hr}$. Control cells were incubated with an equivalent amount of solvent DMSO (up to $0.1 \%$ final concentration). Glial cultures received 1 and $3 \mu \mathrm{M}$ lactacystin for $5 \mathrm{~d}$.

\section{Antibodies}

The following antibodies were used: anti-huntingtin N-terminal CAG53b (amino acids 1-118 with 51 polyglutamines; a kind gift from Dr. Wanker, Berlin, Germany), anti-huntingtin N-terminal EM48 (amino acids 1-256 of human huntingtin; kindly donated by Dr. Li, Atlanta, GA), anti- $\beta 3$ tubulin (Diaz-Nido et al., 1990), anti- $\beta$-tubulin (Sigma), anti- $\beta$ galactosidase (Promega, Madison, WI), and anti-ubiquitin (Dako, High Wycombe, UK).

\section{Immunocytochemistry and immunohistochemistry}

Cell culture. Cultures were fixed in $4 \%$ paraformaldehyde (PFA) in $5 \mathrm{~mm}$ $\mathrm{MgCl}_{2}$-PBS for $20 \mathrm{~min}$ and rinsed three times in PBS. Cultures were pretreated with $1 \%$ BSA, $5 \%$ FBS, and $0.2 \%$ Triton X-100 and incubated for $1 \mathrm{hr}$ with primary antibodies at the following dilutions: anti- $\beta$ galactosidase, 1:5000; CAG53b, 1:5000; anti- $\beta$-tubulin, 1:500; and antiubiquitin, 1:600. Next, cultures were incubated in avidin-biotin complex using the Elite Vectastain kit (Vector Laboratories, Burlingame, CA). Chromogen reactions were performed with diaminobenzidine (Sigma) and $0.003 \% \mathrm{H}_{2} \mathrm{O}_{2}$ for $10 \mathrm{~min}$. Cultures were coverslipped with Fluoromount.

Whole brain. Mice were anesthetized with a xylazine-ketamine solution and transcardially perfused with 4\% PFA in Sorensen's buffer for 10 min. Brains were post-fixed in $4 \%$ PFA for $2 \mathrm{hr}$ at $4^{\circ} \mathrm{C}$ and cryoprotected in $30 \%$ sucrose solution. Coronal sections $(30 \mu \mathrm{m})$ were cut on a freezing microtome (Leica, Nussloch, Germany) and collected in $0.1 \%$ azide-PBS solution. Sections were processed for EM48 and ubiquitin as described previously (Li et al., 1999; Yamamoto et al., 2000).

\section{$\beta$-Galactosidase activity assays}

LacZ staining. Cultures were fixed for $20 \mathrm{~min}$ in $4 \%$ PFA in $5 \mathrm{~mm}$ $\mathrm{MgCl}_{2}-\mathrm{PBS}$. Slides were incubated for $1 \mathrm{hr}$ at $30^{\circ} \mathrm{C}$ in an $\mathrm{X}$-gal solution: $1 \mathrm{mg} / \mathrm{ml} \mathrm{X}$-gal (Boehringer Mannheim, Indianapolis, IN), $5 \mathrm{~mm}$ potassium ferrocyanide, $5 \mathrm{~mm}$ potassium ferricyanide, and $2 \mathrm{mM} \mathrm{MgCl}_{2}$ in PBS. After staining, cultures were coverslipped with Fluoromount.

$O$-nitrophenyl $\beta$-D-calactopyranoside colorimetric assay. Cultures were washed twice with $5 \mathrm{mM} \mathrm{MgCl}_{2}$ in PBS. Cells were lysed in $250 \mathrm{~mm}$ Tris buffer, $\mathrm{pH} 8.0$, with $0.1 \%$ Triton X-100. Enzymatic assay was performed as described previously (Sambrook et al., 1989).

\section{Survival assays}

Propidium iodide-calcein staining. Twenty-four hours after plating, cultures were shifted to media without serum, B27, or both. After 24, 48, or $72 \mathrm{hr}$, cell viability was assessed by propidium iodide-calcein staining (Mattson et al., 1995). Calcein-AM is taken up and cleaved by esterases present within living cells and leads to a yellowish-green fluorescence, whereas propidium iodide (PI) is taken up by only dead cells and become orange-red fluorescent. In brief, neurons were incubated for $30 \mathrm{~min}$ with $2 \mu \mathrm{M}$ PI (Sigma) and $1 \mu \mathrm{M}$ calcein-AM (Molecular Probes, Eugene, OR). After several brief rinses with each medium, cells were visualized by fluorescence microscopy using a Zeiss (Oberkochen, Germany) Axiovert 135 microscope. Four fields (selected at random) were analyzed per well $(\sim 300$ cells per field) in two independent experiments. Cell death was expressed as percentage of PI-positive cells from the total number of cells.

Hoechst 33342 nuclear staining. Neurons were fixed in 4\% PFA in $5 \mathrm{~mm}$ $\mathrm{MgCl}_{2}$-PBS and pretreated with $0.2 \%$ Triton X-100 in PBS. After that, cultures were incubated with Hoechst dye $33342(2.5 \mu \mathrm{g} / \mathrm{ml}$; Biologics) and visualized under a fluorescence microscope. The percentage of condensed or fragmented nuclei was counted for each genotype and culture condition at $20 \times$ magnification. Data are reported as the mean \pm $\operatorname{SEM}(n=3)$.

\section{Western blot analysis}

Cutures were washed twice with $5 \mathrm{~mm} \mathrm{MgCl}_{2}$-PBS. Extracts for Western blot analysis were prepared by homogenizing cells in ice-cold extraction buffer consisting of $20 \mathrm{~mm}$ HEPES, pH 7.4, $100 \mathrm{~mm} \mathrm{NaCl}, 10 \mathrm{~mm} \mathrm{NaF}$, $1 \%$ Triton X-100, $1 \mathrm{~mm}$ sodium orthovanadate, $10 \mathrm{~mm}$ EDTA, and protease inhibitors ( $2 \mathrm{~mm}$ PMSF, $10 \mu \mathrm{g} / \mathrm{ml}$ aprotinin, $10 \mu \mathrm{g} / \mathrm{ml}$ leupeptin, and $10 \mu \mathrm{g} / \mathrm{ml}$ pepstatin). The samples were homogenized at $4^{\circ} \mathrm{C}$, and protein content was determined by Bradford. Total protein $(10 \mu \mathrm{g})$ was electrophoresed on 10\% SDS-PAGE gel and transferred to a nitrocellulose membrane (Schleicher and Schuell). The experiments were performed using the following primary antibodies: anti- $\beta$-tubulin (1:5000), anti- $\beta$-galactosidase (1:5000), and CAG53b (1:5000). The filters were incubated with the antibody at $4^{\circ} \mathrm{C}$ overnight in $5 \%$ nonfat dried milk. A secondary goat anti-mouse (anti- $\beta$-tubulin and anti- $\beta$-galactosidase) or goat anti-rabbit (CAG53b) antibody (both 1:5000; Life Technologies), followed by ECL detection reagents (Amersham Pharmacia Biotech, Arlington Heights, IL), were used for immunodetection. Quantitation of immunoreactivity was performed by densitometric scanning. The densitometry values obtained in the linear range of detection with these antibodies were normalized with respect to the values obtained with an anti- $\beta$-tubulin antibody to correct for any deviation in loaded amounts of protein. Statistical analysis was performed using Student's $t$ test.

\section{Mouse behavior}

Rotarod. Mice were initially trained on the rotarod (Accelerating model; Ugo Basile, Comerio, Italy) at a constant speed ( $20 \mathrm{rpm})$. Mice received four trials per day for 4 consecutive days, by which time a steady level of performance was attained. On the testing day, the rotarod was set to increase from 4 to $40 \mathrm{rpm}$ over $360 \mathrm{sec}$. The interval for mice to fall off was measured twice per day for $2 \mathrm{~d}$. Data were analyzed by repeatedmeasures ANOVA and Fisher's post hoc test when applicable. Data are represented as mean \pm SEM

Locomotion paradigm. Testing was conducted between 11:00 A.M. and 4:00 P.M. Mice were placed in $20 \times 20 \mathrm{~cm}^{2}$ open-field chambers and monitored throughout the test session by a video-tracking system (PolyTrack; San Diego Instruments, San Diego, CA). Up to four animals are monitored simultaneously through a video camera located above the open field. Locomotion and path are recorded every $0.5 \mathrm{sec}$. On the testing day, mice were placed directly in the open field and observed 
continuously for $60 \mathrm{~min}$. Data regarding each animal's path length were collected and summed for each 5 min interval during the test session.

\section{Cell counting}

Free-floating sections $(40 \mu \mathrm{m})$ were mounted on gelatin-subbed slides and processed for thionin staining. A series of measurements running through the striatum at $120 \mu \mathrm{m}$ intervals were taken from brains from 34to 40 -week-old mice. The number of neurons was determined on blindcoded slides with a semiautomated system (Stereoimager). The area of the striatum was traced, and a counting frame was randomly placed within this area. The frame was moved systematically through the striatum, and the cell counts were extrapolated based on a stereologic algorithm. Data were analyzed by factorial ANOVA and presented as mean \pm SEM.

\section{RESULTS}

\section{Striatal primary neuronal cultures from HD94 mice express mutated exon-1 htt in a conditional manner}

In HD94 mice, htt exon 1 protein with a 94 polyglutamine repeat (HD94-htt) and the reporter $\beta$-galactosidase are expressed in the forebrain under the control of the calmodulin-kinase II $\alpha$ $(\mathrm{CaMKII} \alpha)$ promoter in a tetracycline-repressible manner (by using the tetracycline transactivator, tTA) (Fig. 1A) (Yamamoto et al., 2000). Although the activity of the endogenous CaMKII $\alpha$ promoter is postnatal (Vallano, 1990), previous characterization of HD94 mice (Yamamoto et al., 2000) and other conditional transgenic mice generated with the CaMKII $\alpha$-tTA mice (Lucas et al., 2001) suggests prenatal transgene expression. To confirm that the transactivation system functions in postnatal HD94 striatal cultured neurons from the first day in vitro (DIV), we performed Western blot (Fig. 1B,C) and immunocytochemistry (Fig. $1 D-G)$ experiments to detect both HD94-htt and the reporter gene $\beta$-galactosidase (lacZ). As shown in Figure $1 B$, both proteins were detected in protein extracts of DIV1 striatal cultures from HD94 mice but not from single transgenic (CaMKII $\alpha$-tTA or BiTetO) or wild-type mice. The lack of expression in BiTetO single transgenic cultures demonstrated that there is no "leakage" from this construct and that expression is mediated by transactivation via tTA.

After determining that transgene expression was established in the cultures, we next determined how many cells were positive for lacZ. Both immunocytochemistry (Fig. $1 D$ ) and X-gal reactivity (data not shown) revealed that $95 \%$ of the neurons expressed the reporter gene.

The tet system used in HD94 mice allows for regulation of transgene expression by inhibition of transcription in the presence of tetracycline (Gossen and Bujard, 1992). It has been reported previously that a concentration of $1 \mu \mathrm{g} / \mathrm{ml}$ tetracycline is sufficient to exert this control in culture (Gossen and Bujard, 1992). To determine whether this is the case in our primary culture system, we examined LacZ activity after tetracycline treatment. Using an ONPG colormetric assay, we found that a concentration of $1 \mu \mathrm{g} / \mathrm{ml}$ tetracycline was sufficient to yield undetectable $\beta$-galactosidase activity (data not shown). Next, we ascertained the kinetics of silencing of HD94-htt expression. As shown in Figure $1 C$, Western blot analysis revealed a slight decrease in HD94-htt levels $24 \mathrm{hr}$ after addition of $1 \mu \mathrm{g} / \mathrm{ml}$ tetracycline, and the protein could no longer be detected after $72 \mathrm{hr}$.

\section{HD94 cultured neurons show protein aggregates stained with anti-N-terminal htt and anti-ubiquitin antibodies}

Immunocytochemistry with antibodies raised against N-terminal htt (CAG53b and EM48) (Davies et al., 1997; Li et al., 1999) revealed HD94-htt expression in the majority of neurons in culture (Fig. $1 E-G$ ). At DIV1 (Figs. $1 F, G, 2 A$ ), diff use HD94-htt staining was found in the nuclei of all immunostained neurons, and, in a small percentage of neurons, somatodendritic staining was also present. However, after DIV3 (Fig. 2B) (see Fig. 5A), only nuclear staining was detected. Closer examination revealed the presence of HD94-htt-containing aggregates (Fig. $2 A, B$ ) that increased over time (Fig. $2 C$ ). At DIV1, aggregates were present in $13 \%$ of the cells. The percentage of neurons bearing aggregates increased progressively until DIV5 when it reaches a plateau, with $30 \%$ of the neurons bearing inclusions. Most neurons showed a single nuclear inclusion (Fig. $2 A, B$, small black arrows), although neurons with several nuclear inclusions (Fig. $2 A$, large black arrow) (see Fig. 6A) were also found. Occasionally, neurons with cytoplasmic aggregates (either multiple small and dispersed, or a single aggregate by the nucleus) were also found, but only during the first 2-3 d in culture (Fig. 2A, white arrow, and data not shown). Immunocytochemistry against ubiquitin predominantly revealed those neurons with single or multiple intranuclear aggregates (see Fig. 6A).

\section{Formation and reversal of aggregates are rapid processes in culture}

We have established that the postnatal cultures from HD94 mice demonstrate tTA-mediated expression of both transgenes and that tetracycline efficiently abolished transgene expression. We also found that aggregates were present since the beginning of the life of the culture. To determine the rate at which aggregates form, however, the presence of aggregates at DIV1 might complicate the interpretation of the results. Thus, to synchronize aggregate formation, we decided to suppress transgene expression until after plating. This was achieved by maintaining pups on the tetracycline analog doxycycline (dox) from embryonic day 16 to the day of culture, by administering to the mothers $2 \mathrm{mg} / \mathrm{ml}$ dox in their drinking water. Tetracycline was also maintained during the dissociation and removed only at the time of plating. After this protocol, no HD94-htt expression was detected by Western blot or by immunohistochemistry $3 \mathrm{hr}$ after plating (data not shown). HD94-htt is first detected by Western blot at $6 \mathrm{hr}$ and then increases progressively up to DIV3 when it reaches maximal levels (Fig. 3A).

Now that we have synchronized transgene expression to begin after plating, we examined the time required for the formation of aggregates in our primary culture system (Fig. 3B). By DIV3, aggregates were present in $2 \%$ of the neurons, and this percentage steadily increased until DIV6 when it reached plateau. This demonstrates that aggregate formation is a rapid process that requires only $2 \mathrm{~d}$ of HD94-htt expression.

We next decided to study the speed and efficiency of aggregate reversal in culture, by abolishing transgene expression once aggregates were detectable (Fig. $3 B)$. Tetracycline $(1 \mu \mathrm{g} / \mathrm{ml})$ was administered at DIV3 or DIV4. One to $2 \mathrm{~d}$ after addition of tetracycline, the percentage of neurons bearing aggregates continued to increase. This is not surprising because soluble huntingtin required 2-3 d to be abolished (Fig. 1C). Nevertheless, after this initial increase, the number of aggregates began to decrease by day 3 of tetracycline administration, and by day 5 aggregates were no longer present. In summary, whereas aggregate formation required $2 \mathrm{~d}$ of transgene expression, reversal required $5 \mathrm{~d}$ of tetracycline administration, which included 2-3 d for the loss of the soluble fragment. 
A

tTA

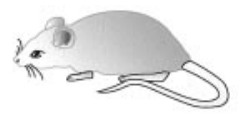

CamKII-tTA $\mathrm{x}$

BiTetO- $\beta$-Gal

/ htt exon-1(CAG) 94
B

wt tTA BiTet0 HD94
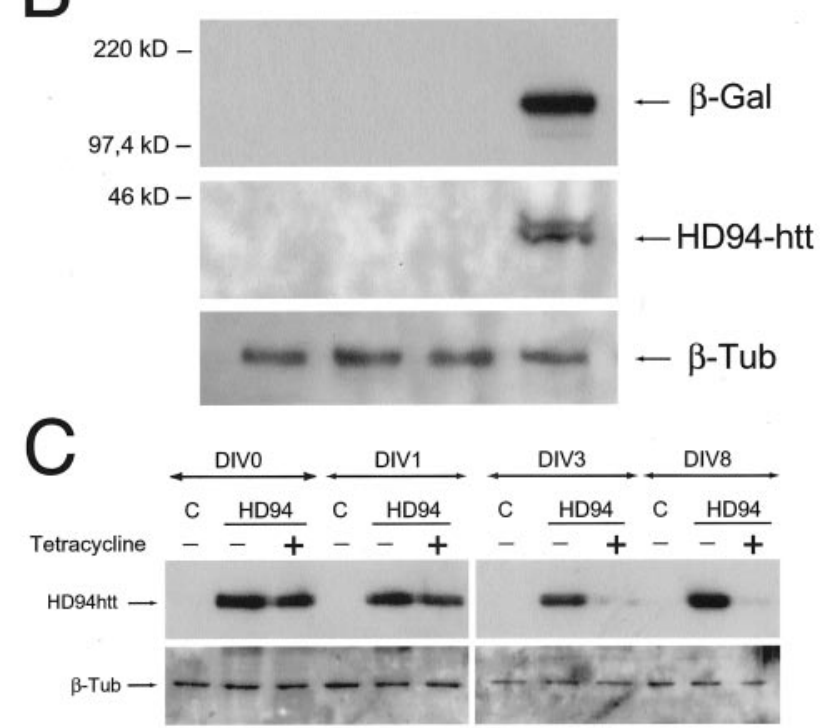

$\mathrm{D}$

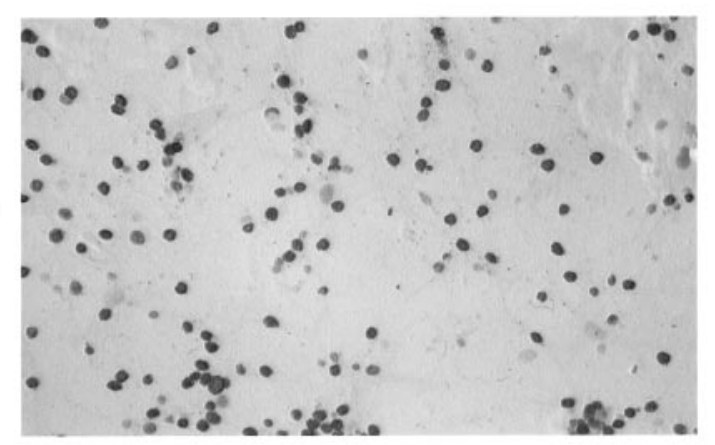

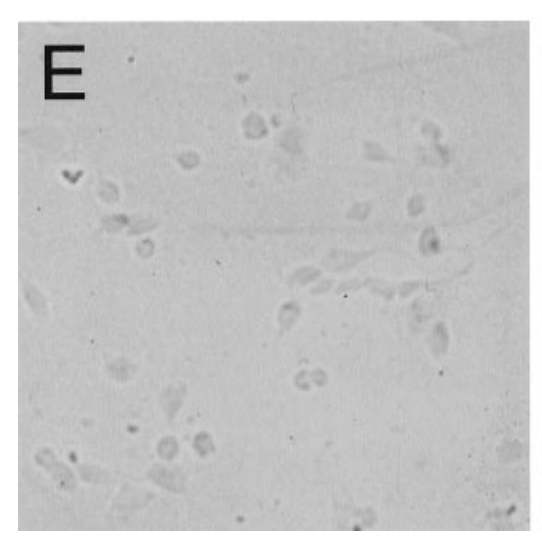
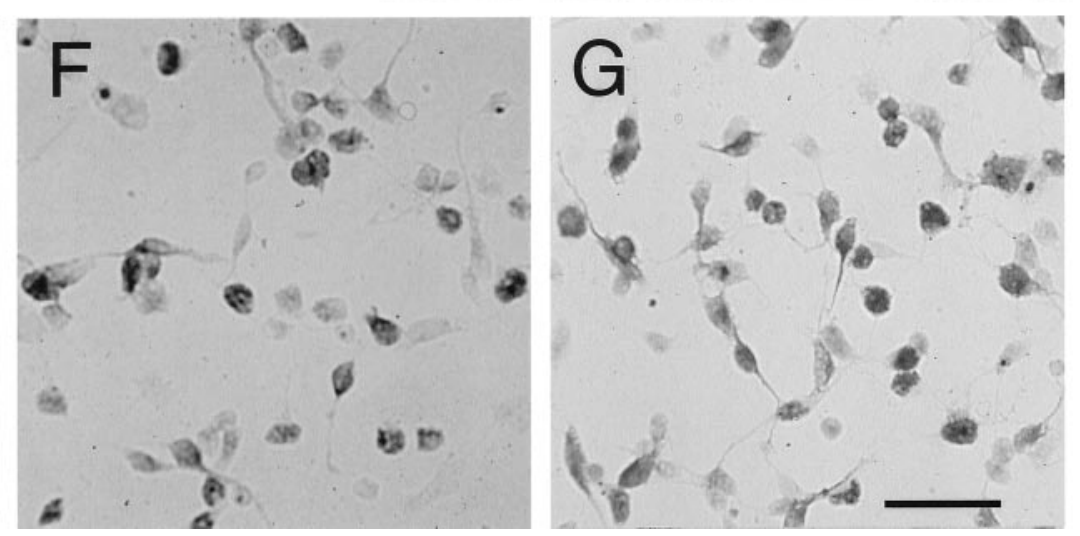

Figure 1. Striatal primary neuronal cultures from HD94 mice express mutated exon-1 htt (HD94-htt) and lacZ in a conditional manner. $A$, HD94 mice are derived from crosses between CaMKII $\alpha$-tTA $(t T A)$ and HD94htt-BiTetO-lacZ (BitTetO) mice. Coexpression of both transgenes allow for tTA-mediated expression of both HD94-htt and $\beta$-galactosidase (lacZ; $\beta$-Gal) in the following manner: tTA binds to the BiTetO sequence to drive expression of HD94-htt and lacZ through a minimal cytomegalovirus promoter. In the presence of tetracycline, tTA undergoes a conformational change that renders it unable to bind to the BiTetO sequence, and transactivation of the transgenes is prevented. $B$, Primary neuronal cultures were prepared from the striata of mice of the four possible genotypes: wild-type, tTA, BiTetO, and HD94. Protein extracts from each culture was prepared at DIV1, and the expression of both transgenic proteins, lacZ and HD94-htt, was analyzed by Western blot. The absence of protein in the BiTetO cultures indicate that no leakage is present, and transgene expression is mediated by tTA. $\beta$-Tub, $\beta$-Tubulin. $C$, Primary cultures from control (BiTetO) and HD94 mice in the presence or absence of $1 \mu \mathrm{g} / \mathrm{ml}$ tetracycline. Protein extracts were prepared at different DIV and probed with antibodies raised against N-terminal htt and $\beta$-tubulin $(\beta$-Tub) antibodies to monitor the decay in HD94-htt levels. HD94-htt protein levels were slightly decreased within $24 \mathrm{hr}$ of $1 \mu \mathrm{g} / \mathrm{ml}$ tetracycline and reached undetectable levels within $72 \mathrm{hr}$. $C$, Control. $D$, Immunostaining for lacZ demonstrates that $95 \%$ of the neurons are positive for the reporter gene. $E-G$, HD94-htt is expressed in the majority of neurons in culture at DIV1 as revealed by immunocytochemistry with antibodies raised against N-terminal htt (CAG53B and EM48). E, control cultures stained with EM48. F, HD94 cultures stained with EM48. $G$, HD94 cultures stained with CAG53b. Scale bar, $50 \mu \mathrm{m}$. 

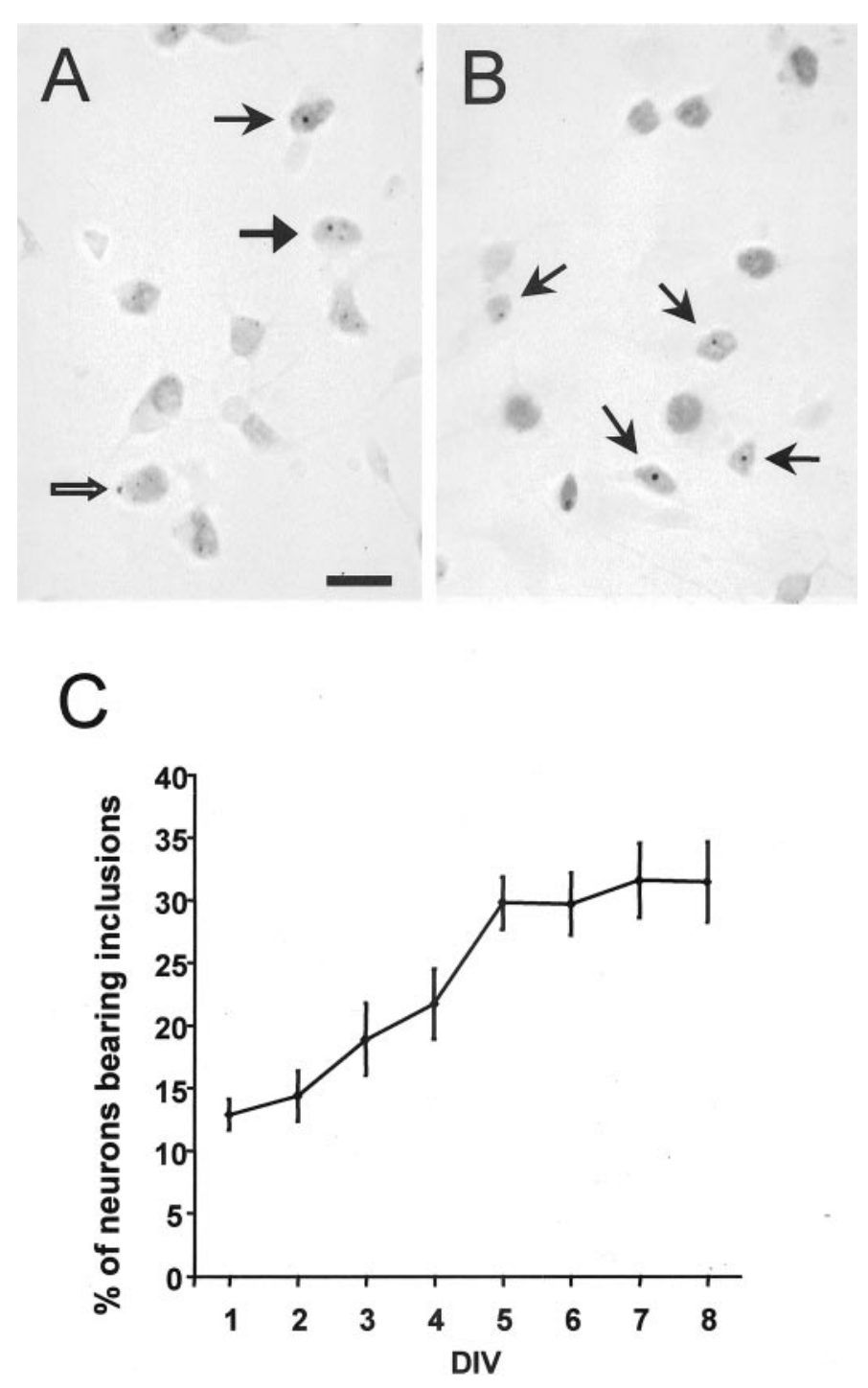

Figure 2. Protein aggregates increase over time in HD94 cultured striatal neurons. Immunocytochemistry with the antibody CAG53b. $A$, At DIV1, different aggregated forms of the protein are present. B, At DIV6, only single intranuclear aggregates can be seen. $C$, The percentage of neurons bearing aggregates plotted over time. The percentage of aggregate-containing neurons continually increases until DIV5 at which time the value reaches a plateau. Arrows denote the different aggregated forms: the white arrow points to cytoplasmic aggregates; large black arrow points to multiple intranuclear aggregates; small black arrows point to single intranuclear aggregates. Scale bar, $30 \mu \mathrm{m}$.

\section{Aggregate reversal in vivo precedes motor recovery}

In light of the rapid reversal of aggregates in the culture model, we were prompted to revisit the time required for aggregates to revert in the HD94 mice. Twelve-week-old symptomatic HD94 mice (Fig. 4D) were stained for HD94-htt using EM48 antibody. In the striatum, intranuclear staining was found (Fig. 4A). Higher magnification and thionin counterstaining (Fig. $4 B$ ) revealed that, at this age, apart from the diffuse intranuclear HD94-htt staining, also cytoplasmic and intranuclear punctate aggregates were found (Fig. 4B). An antibody against ubiquitin revealed some diffuse intranuclear HD94-htt but preferentially stained for the punctate form, albeit in the cytoplasm or intranuclear (data not shown).

To determine the rapidity at which the HD94-htt cleared, mice were treated with $2 \mathrm{mg} / \mathrm{ml}$ dox in the drinking water for 1 or 3
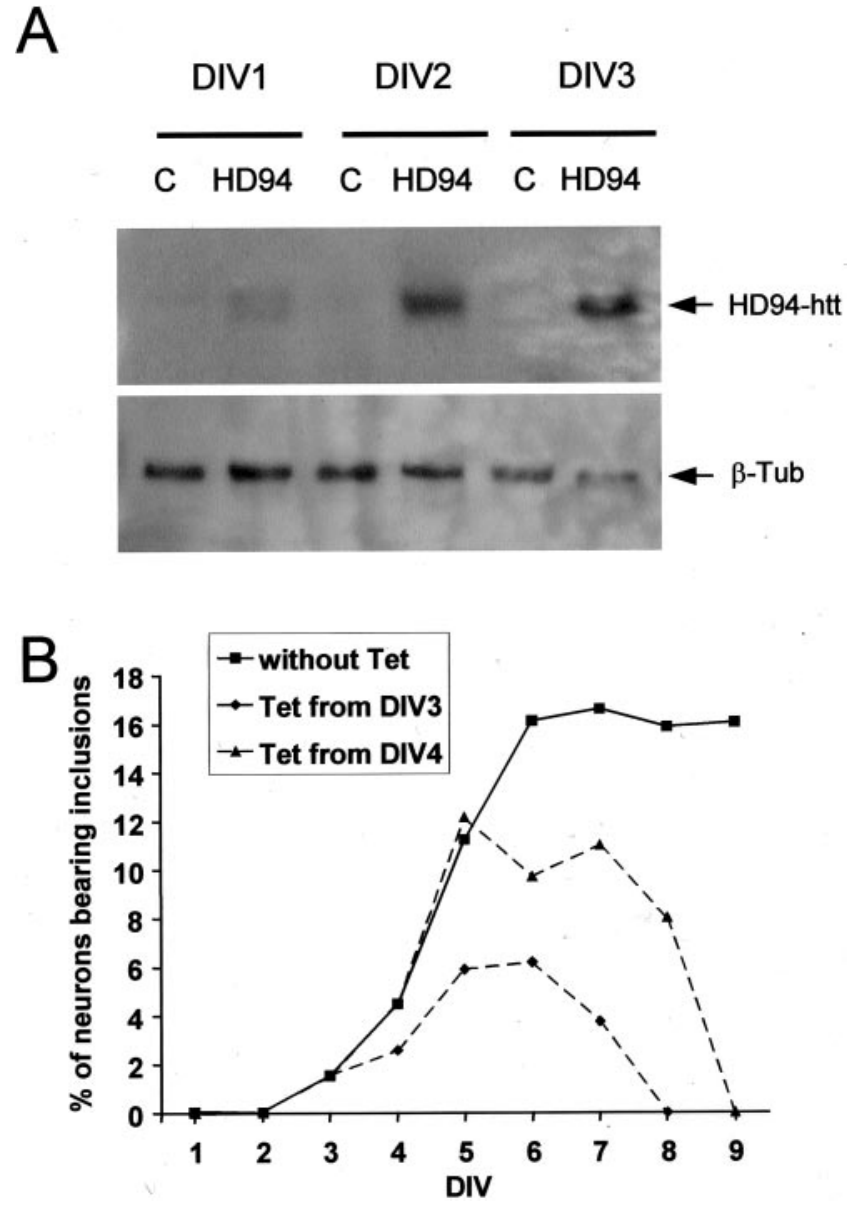

Figure 3. Formation and reversal of aggregates are rapid processes in culture. Cultures were synchronized to begin transgene expression at plating. $A$, Protein extracts were prepared at DIV1, DIV2, and DIV3 and probed with anti-N-terminal htt and anti- $\beta$-tubulin $(\beta$-Tub) antibodies to monitor the initiation of the expression of HD94-htt. $C$, Control. $B$, Progression over time in culture of the percentage of neurons bearing aggregates in the absence of tetracycline or after adding $1 \mu \mathrm{g} / \mathrm{ml}$ tetracycline at DIV3 or at DIV4.

weeks and then assessed for HD94-htt immunostaining. A mild decrease was seen after the 1 week dox treatment (data not shown), whereas after the 3 week treatment, all forms of staining were absent in the regions examined (Fig. 4C).

In light of the speed at which the HD94-htt disappeared from 12-week-old HD94 brains, we next determined whether the motor dysfunction could recover with equal rapidity. To test motor coordination, 12-week-old mice were assessed on an accelerating paradigm on the rotarod (Fig. $4 D$ ). Whereas single transgenic control mice could remain on the rotating rod for close to the full $360 \mathrm{sec}$ duration of the test, HD94 mice fell off the rod significantly sooner. The 12 week group was then split to a no dox group, which continued to express the transgene, and a doxtreated group, which received $2 \mathrm{mg} / \mathrm{ml}$ dox to eliminate transgene expression (Fig. 4D, and data not shown). Mice were tested on the rotarod again after 4 weeks of dox treatment. Although 3 weeks were sufficient for a complete disappearance of HD94-htt from the tissue, rotarod performance was not improved, and mice still failed significantly sooner than control. Retesting mice after 8 weeks of treatment led to a significant recovery, and mice were indistinguishable from the age-matched controls. Control mice 

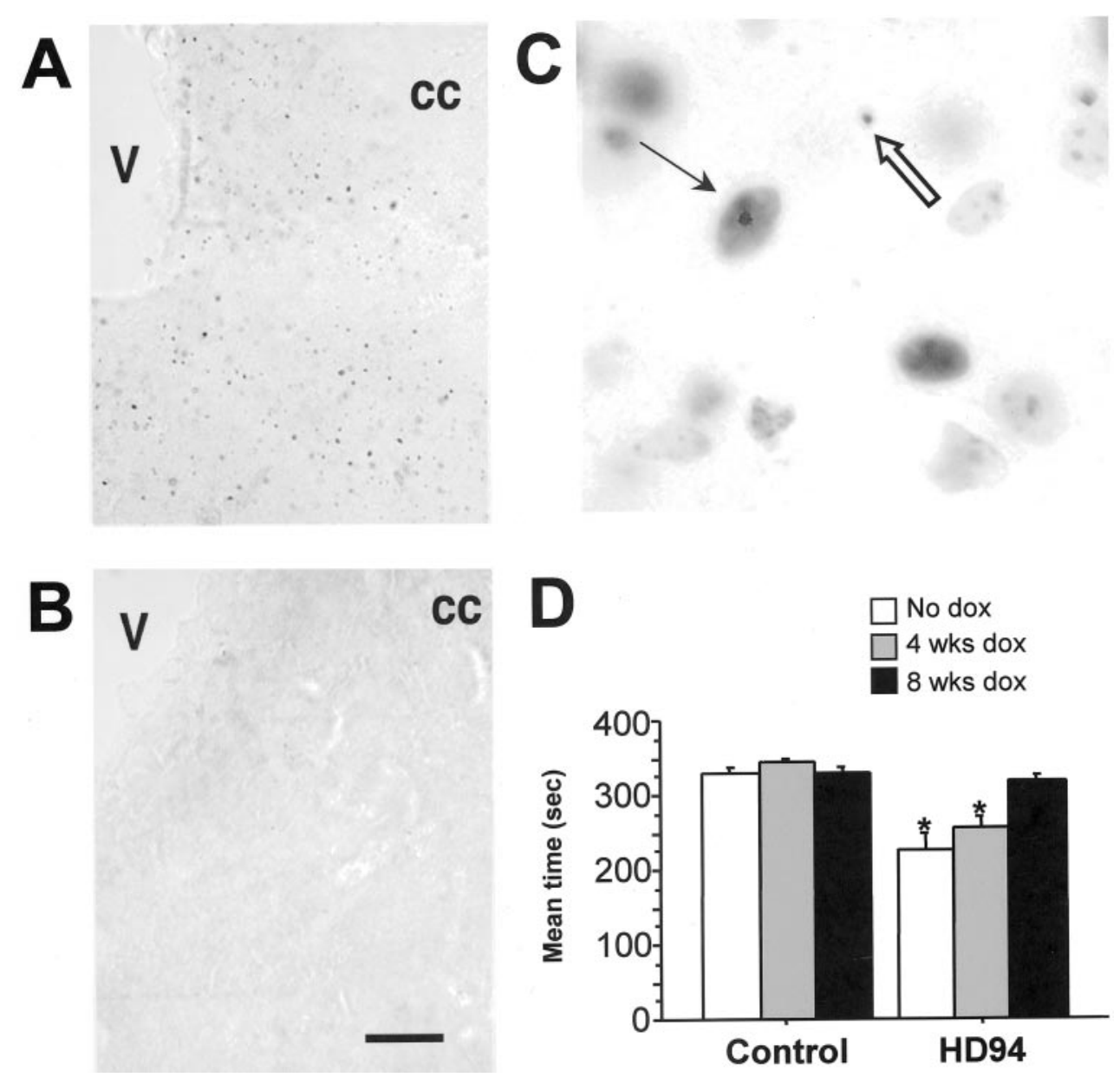

Figure 4. Reversal of aggregates in vivo is faster than motor recovery. Immunostaining of 12-week-old HD94 mice $(A)$ or 12-week-old HD94 mice after 3 weeks of dox treatment $(B) . A$, EM48 reveals HD94-htt expression in striatum. $C$, Costaining of EM48 with thionin demonstrates that HD94-htt is in different forms: diffuse intranuclear, intranuclear aggregates (black arrow), and cytoplasmic aggregates (white arrow). $B$, Three weeks of dox treatment leads to a loss of all forms of HD94-htt staining. $V$, Ventricle; $c c$, corpus callosum. $D$, Mean \pm SEM time spent on rotarod by controls and HD94 mice, after no dox treatment (white bars), 4 weeks of dox treatment (gray bars), and 8 weeks of dox treatment (black bars). Repeated-measures ANOVA revealed a main effect of group $\left(F_{(2,32)}=28.627 ; p<\right.$ $0.0001)$ and an interaction of mean time and group $\left(F_{(4,32)}=8.241 ; p<0.0001\right)$. Post hoc Scheffé analysis demonstrated that HD94 mice lost their balance significantly sooner than controls, even after 4 weeks of dox treatment. After 8 weeks, HD94 mice became indistinguishable from control. ${ }^{*} p<0.001$, significant decrease in mean time on rotarod compared with control. Scale bar, $300 \mu \mathrm{m}$. that received the dox treatment were indistinguishable from the nontreated control group.

\section{Reversal of aggregates is dependent on proteasome activity}

We have thus far demonstrated that the aberrant protein HD94htt can be cleared within $5 \mathrm{~d}$ in culture and 3 weeks in 12-weekold mice after tetracycline is administered. Next, we explored the possible mechanism that might account for the reversal. The aggregates found in HD are often ubiquitinated and colocalize with proteasome subunits (Davies et al., 1997; DiFiglia et al., 1997; Sieradzan et al., 1999; Wyttenbach et al., 2000; Jana et al., 2001). Similarly, several studies suggest an important role of the ubiquitin-proteasome pathway in other polyglutamine repeat disorders (Cummings et al., 1998, 1999; Chai et al., 1999; Stenoien et al., 1999). This, together with the recently reported inhibition of UPS by mutated htt (Bence et al., 2001; Jana et al., 2001) suggests that proteasome degradation mediates the clearance of aggregates and/or of soluble htt. We therefore tested this hypothesis by using the irreversible proteasome inhibitor lactacystin in the culture model.

HD94 striatal neuronal cultures were prepared in which transgene expression was activated right after plating (as described above). Tetracycline was added at DIV4, DIV5, or DIV6 to stop HD94-htt expression. Then, 3 d after the tetracycline, a mild lactacystin treatment was administered to the culture (400 nM to $1 \mu \mathrm{M}$ ) for $2 \mathrm{~d}$, and the effect of lactacystin treatment on aggregate reversal was analyzed. As shown in Figure $5 A, 5 \mathrm{~d}$ of tetracycline in the absence of lactacystin resulted in a reduction of the percentage of neurons with aggregates to $1.5 \%$. However, when lactacystin was present for the last $48 \mathrm{hr}$, the percentage of neurons with aggregates was more than double $(3.6 \% ; p=0.0012)$. Therefore, without proper proteasome activity, the aggregate reversal demonstrated previously was significantly hindered.

The postnatal neuronal cultures were quite sensitive to lactacystin and could resist only mild and short treatments. We then decided to study whether the lack of aggregate clearance by lactacystin-treated neurons could be reproduced in other cell types that better resist lactacystin treatments. For this reason, we performed similar experiments on primary glial cultures that were derived from HD94 striata. The glial cultures also showed HD94-htt expression and aggregates (Fig. 5B,C). At DIV9, confluent HD94 glial cultures were given tetracycline alone $(1 \mu \mathrm{g} / \mathrm{ml})$ or in combination with lactacystin $(1-3 \mu \mathrm{M})$. As shown in Figure $5 B, 5 \mathrm{~d}$ of transgene silencing with tetracycline resulted in full supression of both HD94-htt expression and aggregates. However, when the proteasome activity was also inhibited, both diffuse and aggregate staining remained. Thus, the aggregate reversal demonstrated in the glial culture was also dependent on fully functional proteasome activity. Together, these results suggested that aggregate formation depends on soluble HD94-htt intracellular concentration and that this, in turn, is a balance between the rate of synthesis and rate of proteasome-mediated degradation of htt. 
Figure 5. Reversal of aggregates is dependent on proteasome activity. $A, \mathrm{HD} 94$ striatal neuronal cultures were given 1 $\mu \mathrm{g} / \mathrm{ml}$ tetracycline (Tet) at DIV4. Three days later at DIV7, when the percentage of neurons showing aggregates is decreasing, $1 \mu \mathrm{M}$ lactacystin (Lact) or vehicle is added. At DIV9, cells were fixed and immunostained with CAG53b antibody. Although abolishing expression of HD94-htt presence of lactacystin significantly prevented the clearance $(p<0.05)$. B, $C$, HD94 striatal glial cultures were given at DIV9 $1 \mu \mathrm{g} / \mathrm{ml}$ tetracycline with or without $1 \mu \mathrm{M}$ lactacystin. Five days later at DIV14, cells were fixed and immunostained with CAG53b antibody. In the absence of lactacystin $(B)$, both aggregates and diffuse staining fully revert. However, this is prevented by the lactacystin treatment $(C)$. Scale bar, $20 \mu \mathrm{m}$. leads to a clearance of aggregates, the
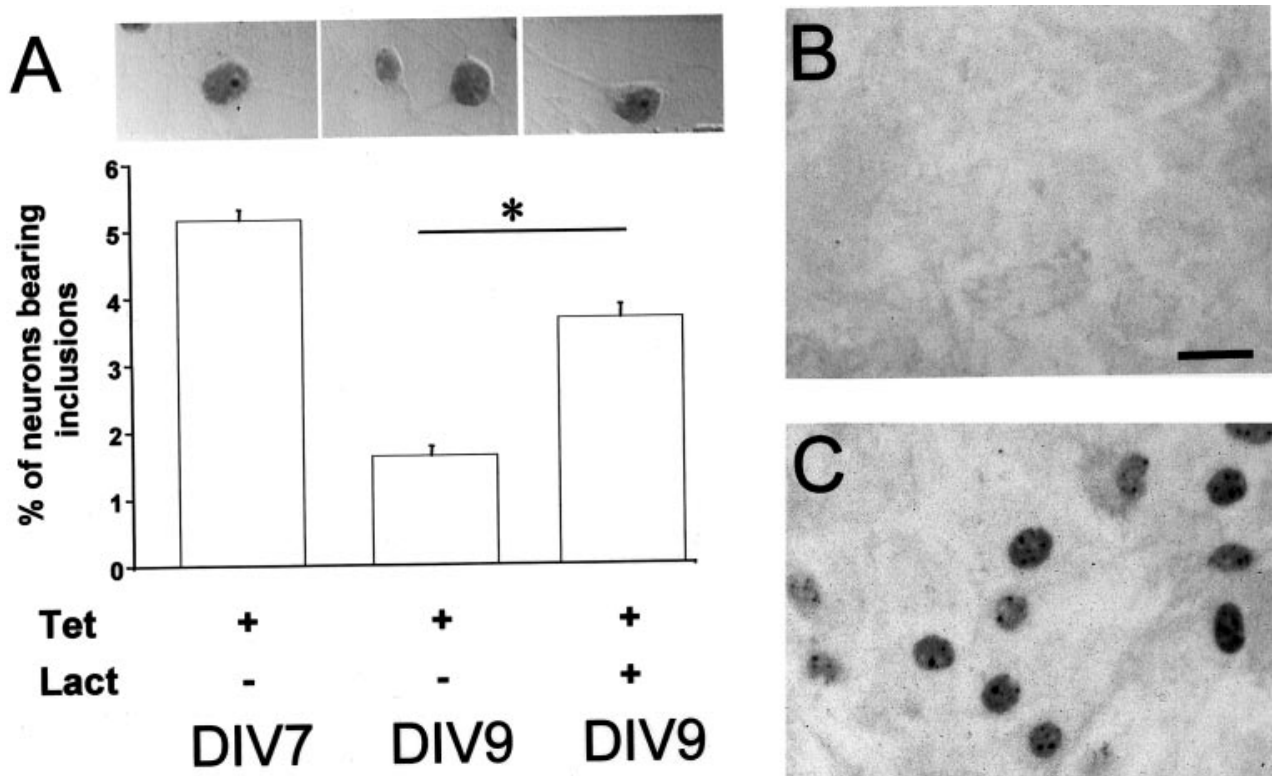

\section{Expression of mutated htt fragment does not affect survival of cultured neurons}

In vitro experiments that rely on transfection to induce expression of mutant forms of huntingtin often demonstrate that expression of these proteins lead to cell death (Saudou et al., 1998; Kim et al., 1999; Waelter et al., 2001). We therefore examined whether similar observations could be made in the primary cultures.

Neuronal death was first investigated by examining the nuclear morphology of those neurons showing aggregates. Aggregates were stained with anti-htt or anti-ubiquitin antibodies (Fig. 6A), and the nuclear morphology was revealed by Hoechst labeling (Fig. 6B). As exemplified in Figure 6, $A$ and $B$, no correlation between the presence of aggregates and condensed or fragmented nuclei was found. Next, to investigate whether HD94-htt expression affected survival of the neuronal cultures, we compared survival of single transgenic control cultures and HD94 cultures, in the presence and absence of tetracycline (Fig. $6 C-G$ ). This was assessed every $24 \mathrm{hr}$ from DIV1 to DIV12, by comparing the percentage of living neurons with dead neurons using Hoechst staining and propidium iodine-calcein double labeling (Fig. $6 C-F$ ) or by counting the total number of neurons (Fig. $6 G$, and data not shown). No difference in the viability between any of the groups was observed. The lack of neuronal death despite transgene expression was reproduced under different paradigms of trophic withdrawal as well (Fig. $6 C-E$, and data not shown).

\section{Absence of neuronal cell death in the atrophied striatum of symptomatic HD94 mice}

The lack of effect of HD94-htt expression on neuronal survival appears to contradict the progressive reduction in striatal volume found in HD94 mice (Yamamoto et al., 2000). It is possible that the lack of cell death in the culture system may be attributable to the short life span of the culture. In older mice, however, cell death may have occurred. To explore whether neuronal death contributes to the decrease in size of HD94 striata, we performed stereological analysis of the striatum of 34- to 40-week-old HD94 mice. At this age, HD94 mice exhibit abnormal clasping behavior (Yamamoto et al., 2000) and hypolocomotor activity when placed in the open field (Fig. 7A). Gross examination of brains from these animals show a marked reduction in striatal size, comple- mented with an enlargement of the lateral ventricle (Fig. $7 B, C$ ). Despite these differences, cell counts demonstrated no difference between HD94 mice and controls at this age (Fig. 7D).

\section{DISCUSSION}

In this study, we have used both HD94 mice and HD94 primary striatal cultures to explore the rate of htt accumulation and clearance, the possible underlying mechanisms and the relationship between HD94-htt expression, aggregates, and cell death. We report the following: that aggregate formation and reversal are rapid processes in culture; that full reversal of striatal aggregates is also rapid in vivo and faster than motor recovery; that aggregate reversal is dependent on proteasome activity; and that HD94-htt expression does not affect neuronal survival, neither in culture nor in vivo in symptomatic HD94 mice.

Aggregates and motor symptoms reverted in parallel in HD94 mice during silencing of transgene expression with long doxycycline treatment (Yamamoto et al., 2000), thus precluding the determination of whether aggregates were causative of the disease. Furthermore, the long-term suppression and reversal did not allow to capture the critical determinants of the recovery. In this study, we revisit the issue of reversal but explore instead the effect of shorter periods of transgene suppression. Additionally, the possible correlation of aggregates and neuronal death was analyzed in primary cultures derived from HD94 mice.

We found that all forms of HD94-htt cleared within 3 weeks in brains of 12-week-old HD94 mice. On the other hand, the motor recovery as measured by rotarod performance required 8 weeks. Although it may be tempting to interpret these findings as aggregate reversal leading to functional improvement, this is difficult to do. As an alternative, our result may be reflecting that the molecular mechanism by which aggregates assemble and disassemble is rapid, whereas motor recovery after transgene silencing probably involves changes in gene expression, morphology, and connectivity that require longer times. Nonetheless, we have narrowed the window of recovery to a period of 5-8 weeks. We are currently pursuing the possible changes that may account for the recovery, by exploring changes in cytoskeletal proteins, plasticity, and changes in RNA levels using cDNA arrays. 

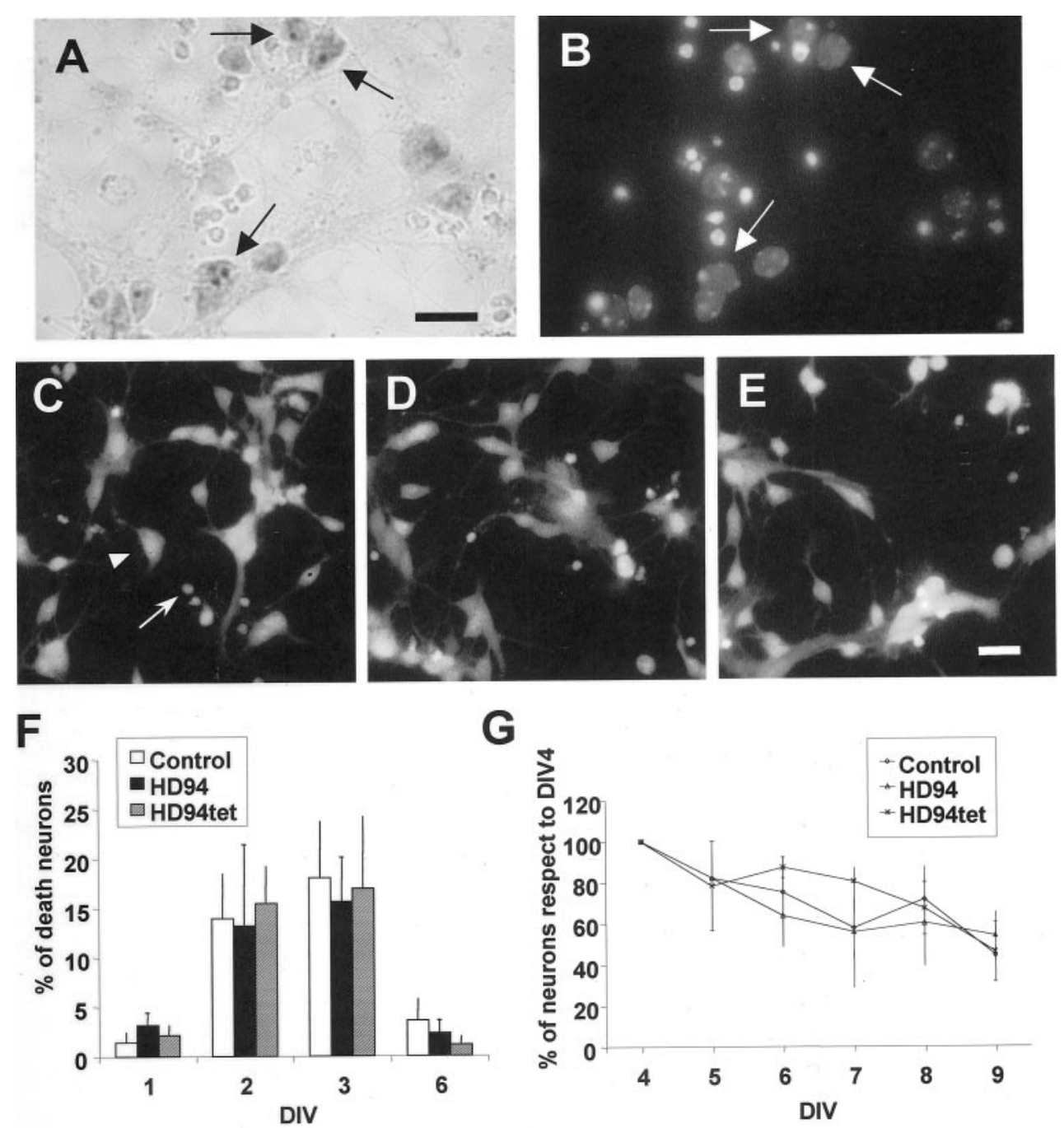

G

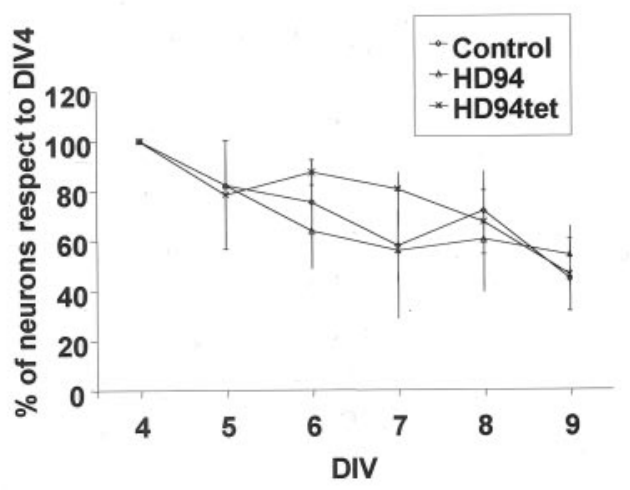

Figure 6. Expression of HD94-htt does not affect survival of striatal cultured neurons. $A$, Anti-ubiquitin immunocytochemistry; $B$, Hoechst nuclear staining of the same field of DIV6 HD94 striatal neuronal culture. Arrows in $A$ and $B$ show neurons with aggregates and normal nuclear morphology. $C-E$, Propidium iodide-calcein staining after trophic withdrawal. Propidium iodide stains apoptotic nuclei (see arrow in $C$ as an example), whereas calcein stains the whole body of live cells (see arrowhead in $C$ as an example). Control $(C)$, HD94 in the absence of tetracycline $(D)$, or HD94 in the presence of 1 $\mu \mathrm{g} / \mathrm{ml}$ tetracycline $(E)$ cultures were prepared as described in Materials and Methods. Twenty-four hours after plating, cultures were shifted to media lacking serum, and, $72 \mathrm{hr}$ later, cell viability was assessed. $F$, After normal culture conditions and Hoechst nuclear staining, the percentage of condensed or fragmented nuclei was counted for each genotype and culture condition at DIV1-DIV6. Counting was performed at $100 \times$ magnification in three different fields of 100 cells each and is reported as the mean $\pm \operatorname{SEM}(n=3)$. $G$, Evolution from DIV4 to DIV9 of the number of neurons immunostained with anti- $\beta$-tubulin in control and HD94 cultures in the presence or absence of 1 $\mu \mathrm{g} / \mathrm{ml}$ tetracycline. Four fields (selected at random) were analyzed per well $(\sim 300$ cells per field) in two independent experiments. Scale bars: $A, 20 \mu \mathrm{m} ; E, 50 \mu \mathrm{m}$.
Regarding the time frame for aggregate formation, this was already found to be brief in vitro and in transfected non-neuronal cell lines (Scherzinger et al., 1997, 1999). Here we established that, in cultured striatal neurons, $2 \mathrm{~d}$ of transgene expression is sufficient for aggregate formation. Aggregate reversal occurred with similar speed, requiring a total of $5 \mathrm{~d}$ of transgene suppression, 2-3 d of which were required to achieve undetectable levels of soluble HD94-htt.

A surprising observation from the work performed in primary cultures was the lack of correlation between aggregate formation and neuronal death. This, however, fits with several studies performed on HD postmortem tissue (Kuemmerle et al., 1999) and on other polyglutamine disease animal models (Klement et al., 1998; Reddy et al., 1998; Huynh et al., 2000; Simeoni et al., 2000) that support the notion that aggregates do not cause disease. Even more surprising was the fact that neither aggregated nor soluble HD94-htt expression promoted neuronal death. This initially seemed to contradict previous reports of cell death induced by the mutated huntingtin (Saudou et al., 1998; Kim et al., 1999; Nucifora et al., 2001; Waelter et al., 2001). However, unlike in the HD94 primary cultures, these experiments depended on transfection of mutated huntingtin. Transient transfection leads to massive levels of overexpression in a low percentage of cells. However, the overexpression in primary cultured neurons is less artifactual than the one attained in transfection experiments. The reason for this is that, during the establishment of the transgenic mouse line, the level of striatal expression of the transgene is adjusted to a maximum compatible with the progression to adult life. Interestingly, most HD94 primary culture neurons express the transgene, and they do so at a level high enough to yield diffuse and aggregated immunocytochemical staining, as well as detection by Western blot.

The lack of HD94-htt-induced neuronal death in culture correlated to the lack of cell loss in the striatum of 40 -week-old symptomatic HD94 mice. Together, this demonstrates that mutated htt primarily induce neuronal dysfunction. In postmortem samples of symptomatic HD patients, aggregates are primarily present in regions that demonstrate little to no cell loss (Gutekunst et al., 1999). Also in good agreement, a few individuals positive for the mutation have been shown to demonstrate no gross neurological changes (Persichetti et al., 1994), also designated grade 0 in Vonsatel staging of HD neuropathology (Vonsattel et al., 1985). Nevertheless, significant levels of neuronal death have been demonstrated in postmortem tissue of later stages of HD (Vonsattel et al., 1985; Portera-Cailliau et al., 1995). Hence, HD progression may have an initial period of neuronal dysfunction during which there is initiation and maintenance of the disease, followed by a second period during which neuronal loss would contribute and exacerbate the symptoms. Similar results suggesting that neuronal dysfunction rather than death is 

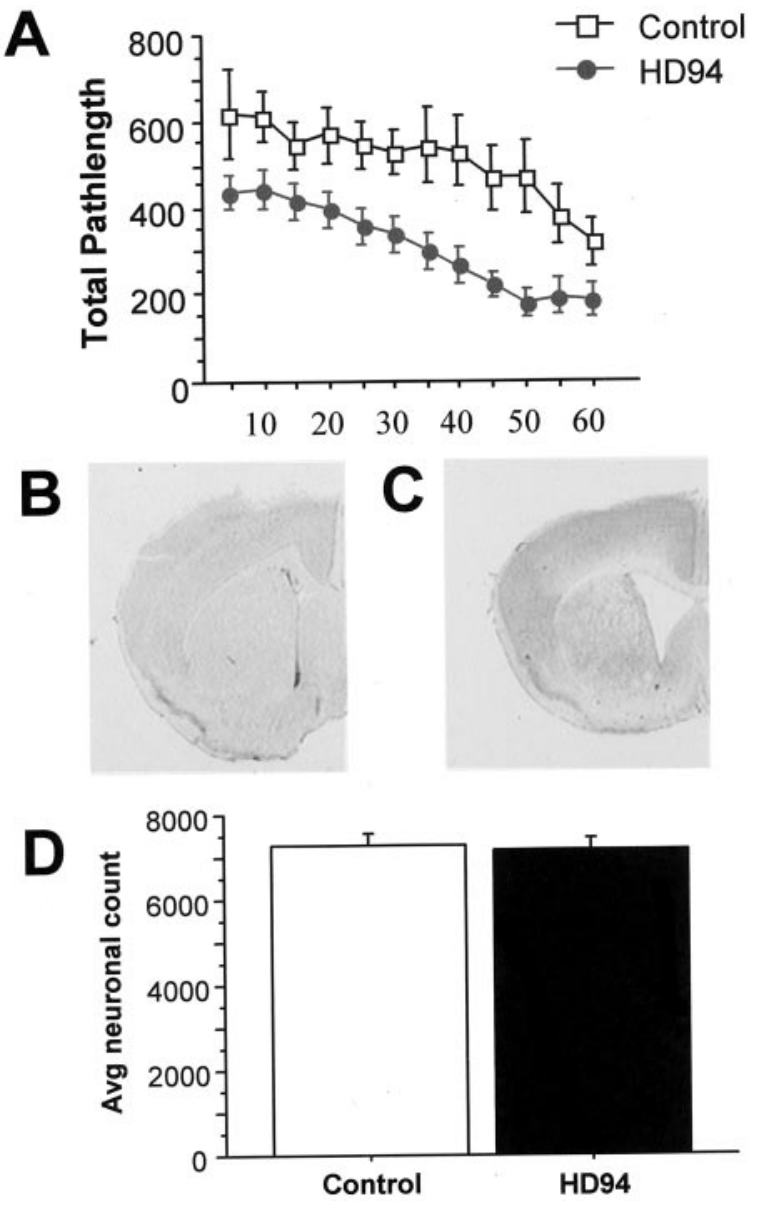

Figure 7. Symptomatic HD94 mice show significant striatal atrophy in the absence of cell loss. $A$, Mean \pm SEM path length traversed by 40-week-old control mice (open squares) and 40-week-old HD94 mice (black circles) in 5 min intervals. Mice were monitored for $1 \mathrm{hr}$. Repeatedmeasures ANOVA revealed a main effect of group $\left(F_{(1,34)}=9.720 ; p<\right.$ $0.005)$ and an interaction between path length and group $\left(F_{(11,34)}=\right.$ 18.100; $p<0.0001)$. $B, C$, Single hemisphere from control and HD94 mice after thionin staining. $D$, Stereologic counts from control and HD94 mice. No significant difference was seen between the groups.

responsible for the early phenotypic manifestations have been reported recently in a mouse model of spinal and bulbar muscular atrophy (Adachi et al., 2001).

Stereological analyses of other HD mouse models have been performed. Asymptomatic R6/1 mice do not demonstrate cell death (Hansson et al., 1999), but whether neuronal death is present after onset of symptoms is unknown. A similar model, the R6/2, however, has been reported to show late stage cell loss (Turmaine et al., 2000). Symptomatic full-length cDNA HD mice have also been reported to show no cell loss (Guidetti et al., 2001) until the mice are at end stage (Reddy et al., 1998). Although changes in neuronal arborization were found in this recent study (Guidetti et al., 2001), striatal atrophy had not yet taken place in those mice. Despite the differences between the numerous HD models available, evidence of a "dysfunctional period" is emerging (Tobin and Signer, 2000). Understanding this period will be critical for therapeutic strategies in polyQ diseases as a whole.

The rapid aggregate reversal was inhibited when lactacystin was administered to the primary neurons. Our findings demonstrated that proteasome activity steadily degrades soluble and aggregated forms of HD94-htt. Similarly, several groups have found that proteasome inhibition leads to an increase in the number of cells containing aggregates (Scherzinger et al., 1999; Wyttenbach et al., 2000; Jana et al., 2001; Waelter et al., 2001). Colocalization of htt-containing aggregates with ubiquitin and proteasome subunits (Davies et al., 1997; DiFiglia et al., 1997; Sieradzan et al., 1999; Jana et al., 2001) have lead to the hypothesis that aggregates may cause dysfunction through inhibition of the UPS. Experiments in a mouse model of another polyQ disease, spinocerebellar ataxia type 1 , have shown that interference with a ubiquitin-protein ligase leads to a decrease in the number of intranuclear aggregates (Cummings et al., 1999). Furthermore, recent findings reveal that UPS is inhibited in transfected cells expressing a mutant form of htt. Inhibition was also seen overexpressing a folding mutant of cystic fibrosis transmembrane conductance regulator (Bence et al., 2001), hence extending this hypothesis to diseases with protein inclusions as a whole.

Proteasome activity has been shown to decline with age in brain tissue (Keller et al., 2000a,b). Because we have shown that protesasome activity counteracts accumulation of both soluble and aggregated htt, the decline with age of proteasome activity may explain the late onset of HD symptomatology. Accordingly, boosting proteasome and/or chaperone cell systems may help to delay onset and progression of HD (Orr and Zoghbi, 2000).

In summary, the data presented here strongly indicate that neuronal dysfunction rather than cell loss underlies HD and further support that reversal of neuropathology and symptoms may be feasible in HD. An increasing number of reports indicate that the dysfunction may lie in the ubiquitin proteasome system. Nevertheless, if the level of mutated htt is decreased, we find that neurons have the ability to recover. Finally, our results also suggest that, together with decreasing mutant htt expression, preventing the decline in proteasome activity may also be of therapeutic relevance.

\section{REFERENCES}

Adachi H, Kume A, Li M, Nakagomi Y, Niwa H, Do J, Sang C, Kobayashi Y, Doyu M, Sobue G (2001) Transgenic mice with an expanded CAG repeat controlled by the human AR promoter show polyglutamine nuclear inclusions and neuronal dysfunction without neuronal cell death. Hum Mol Genet 10:1039-1048.

Ambrose CM, Duyao MP, Barnes G, Bates GP, Lin CS, Srinidhi J, Baxendale S, Hummerich H, Lehrach H, Altherr M, et al. (1994) Structure and expression of the Huntington's disease gene: evidence against simple inactivation due to an expanded $\mathrm{CAG}$ repeat. Somat Cell Mol Genet 20:27-38

Bence NF, Sampat RM, Kopito RR (2001) Impairment of the ubiquitinproteasome system by protein aggregation. Science 292:1552-1555

Chai Y, Koppenhafer SL, Shoesmith SJ, Perez MK, Paulson HL (1999) Evidence for proteasome involvement in polyglutamine disease: localization to nuclear inclusions in SCA3/MJD and suppression of polyglutamine aggregation in vitro. Hum Mol Genet 8:673-682.

Cummings CJ, Mancini MA, Antalffy B, DeFranco DB, Orr HT, Zoghbi HY (1998) Chaperone suppression of aggregation and altered subcellular proteasome localization imply protein misfolding in SCA1. Nat Genet 19:148-154.

Cummings CJ, Reinstein E, Sun Y, Antalffy B, Jiang Y, Ciechanover A Orr HT, Beaudet AL, Zoghbi HY (1999) Mutation of the E6-AP ubiquitin ligase reduces nuclear inclusion frequency while accelerating polyglutamine-induced pathology in SCA1 mice. Neuron 24:879-892.

Davies SW, Turmaine M, Cozens BA, DiFiglia M, Sharp AH, Ross CA, Scherzinger E, Wanker EE, Mangiarini L, Bates GP (1997) Formation of neuronal intranuclear inclusions underlies the neurological dysfunction in mice transgenic for the HD mutation. Cell 90:537-548.

Diaz-Nido J, Serrano L, Lopez-Otin C, Vandekerckhove J, Avila J (1990) Phosphorylation of a neuronal-specific beta-tubulin isotype. J Biol Chem 265:13949-13954.

DiFiglia M, Sapp E, Chase K, Davies S, Bates G, Vonsattel J, Aronin N (1997) Aggregation of huntingtin in neuronal intranuclear inclusions and dystrophic neurites in brain. Science 277:1990-1993.

Dubinsky JM (1989) Development of inhibitory synapses among striatal neurons in vitro. J Neurosci 9:3955-3965.

Gossen M, Bujard H (1992) Tight control of gene expression in mam- 
malian cells by tetracycline-responsive promoters. Proc Natl Acad Sci USA 89:5547-5551.

Guidetti P, Charles V, Chen EY, Reddy PH, Kordower JH, Whetsell Jr WO, Schwarcz R, Tagle DA (2001) Early degenerative changes in transgenic mice expressing mutant huntingtin involve dendritic abnormalities but no impairment of mitochondrial energy production. Exp Neurol 169:340-350.

Gusella JF, MacDonald ME (1996) Trinucleotide instability: a repeating theme in human inherited disorders. Annu Rev Med 47:201-209.

Gutekunst CA, Li SH, Yi H, Mulroy JS, Kuemmerle S, Jones R, Rye D, Ferrante RJ, Hersch SM, Li XJ (1999) Nuclear and neuropil aggregates in Huntington's disease: relationship to neuropathology. J Neurosci 19:2522-2534.

Hansson O, Peters A, Leist M, Nicotera P, Castilho RF, Brundin P (1999) Transgenic mice expressing a Huntington's disease mutation are resistant to quinolinic acid-induced striatal excitotoxicity. Proc Natl Acad Sci USA 96:8727-8732.

Huettner JE, Baughman RW (1986) Primary culture of identified neurons from the visual cortex of postnatal rats. J Neurosci 6:3044-3060.

Huynh DP, Figueroa K, Hoang N, Pulst SM (2000) Nuclear localization or inclusion body formation of ataxin-2 are not necessary for SCA2 pathogenesis in mouse or human. Nat Genet 26:44-50.

Jana NR, Zemskov EA, Wang G, Nukina N (2001) Altered proteasomal function due to the expression of polyglutamine-expanded truncated $\mathrm{N}$-terminal huntingtin induces apoptosis by caspase activation through mitochondrial cytochrome c release. Hum Mol Genet 10:1049-1059.

Keller JN, Huang FF, Markesbery WR (2000a) Decreased levels of proteasome activity and proteasome expression in aging spinal cord. Neuroscience 98:149-156.

Keller JN, Hanni KB, Markesbery WR (2000b) Possible involvement of proteasome inhibition in aging: implications for oxidative stress. Mech Ageing Dev 113:61-70.

Kim M, Lee HS, LaForet G, McIntyre C, Martin EJ, Chang P, Kim TW, Williams M, Reddy PH, Tagle D, Boyce FM, Won L, Heller A, Aronin N, DiFiglia M (1999) Mutant huntingtin expression in clonal striatal cells: dissociation of inclusion formation and neuronal survival by caspase inhibition. J Neurosci 19:964-973.

Klement IA, Skinner PJ, Kaytor MD, Yi H, Hersch SM, Clark HB, Zoghbi HY, Orr HT (1998) Ataxin-1 nuclear localization and aggregation: role in polyglutamine-induced disease in SCA1 transgenic mice. Cell 95:41-53.

Kuemmerle S, Gutekunst CA, Klein AM, Li XJ, Li SH, Beal MF, Hersch SM, Ferrante RJ (1999) Huntington aggregates may not predict neuronal death in Huntington's disease. Ann Neurol 46:842-849.

Li H, Li SH, Cheng AL, Mangiarini L, Bates GP, Li XJ (1999) Ultrastructural localization and progressive formation of neuropil aggregates in Huntington's disease transgenic mice. Hum Mol Genet 8:1227-1236.

Lucas JJ, Hernandez F, Gomez-Ramos P, Moran MA, Hen R, Avila J (2001) Decreased nuclear beta-catenin, tau hyperphosphorylation and neurodegeneration in GSK-3beta conditional transgenic mice. EMBO J 20:27-39.

Mattson MP, Barger SW, Begley JG, Mark RJ (1995) Calcium, free radicals, and excitotoxic neuronal death in primary cell culture. Methods Cell Biol 46:187-216.

Nakamura K, Jeong SY, Uchihara T, Anno M, Nagashima K, Nagashima T, Ikeda S, Tsuji S, Kanazawa I (2001) SCA17, a novel autosomal dominant cerebellar ataxia caused by an expanded polyglutamine in TATA-binding protein. Hum Mol Genet 10:1441-1448.

Nucifora Jr FC, Sasaki M, Peters MF, Huang H, Cooper JK, Yamada M, Takahashi H, Tsuji S, Troncoso J, Dawson VL, Dawson TM, Ross CA (2001) Interference by huntingtin and atrophin-1 with cbp-mediated transcription leading to cellular toxicity. Science 291:2423-2428.

Orr HT, Zoghbi HY (2000) Reversing neurodegeneration: a promise unfolds. Cell 101:1-4.

Persichetti F, Srinidhi J, Kanaley L, Ge P, Myers RH, D’Arrigo K, Barnes GT, MacDonald ME, Vonsattel JP, Gusella JF, et al. (1994) Huntington's disease CAG trinucleotide repeats in pathologically confirmed post-mortem brains. Neurobiol Dis 1:159-166.

Portera-Cailliau C, Hedreen JC, Price DL, Koliatsos VE (1995) Evidence for apoptotic cell death in Huntington disease and excitotoxic animal models. J Neurosci 15:3775-3787.

Price DL, Sisodia SS, Borchelt DR (1998) Genetic neurodegenerative diseases: the human illness and transgenic models. Science 282:1079-1083.

Reddy PH, Williams M, Charles V, Garrett L, Pike-Buchanan L, Whetsell Jr WO, Miller G, Tagle DA (1998) Behavioural abnormalities and selective neuronal loss in $\mathrm{HD}$ transgenic mice expressing mutated full-length HD cDNA. Nat Genet 20:198-202.

Ross CA (1997) Intranuclear neuronal inclusions: a common pathogenic mechanism for glutamine-repeat neurodegenerative diseases? Neuron 19:1147-1150.

Rubinsztein DC, Amos W, Leggo J, Goodburn S, Ramesar RS, Old J Bontrop R, McMahon R, Barton DE, Ferguson-Smith MA (1994) Mutational bias provides a model for the evolution of Huntington's disease and predicts a general increase in disease prevalence. Nat Genet 7:525-530.

Sambrook J, Fritsch EF, Maniatis T (1989) Molecular cloning. A laboratory manual, Ed 2. Cold Spring Harbor, NY: Cold Spring Harbor Laboratory.

Saudou F, Finkbeiner S, Devys D, Greenberg ME (1998) Huntingtin acts in the nucleus to induce apoptosis but death does not correlate with the formation of intranuclear inclusions. Cell 95:55-66.

Scherzinger E, Lurz R, Turmaine M, Mangiarini L, Hollenbach B, Hasenbank R, Bates GP, Davies SW, Lehrach H, Wanker EE (1997) Huntingtin-encoded polyglutamine expansions form amyloid-like protein aggregates in vitro and in vivo. Cell 90:549-558.

Scherzinger E, Sittler A, Schweiger K, Heiser V, Lurz R, Hasenbank R, Bates GP, Lehrach H, Wanker EE (1999) Self-assembly of polyglutamine-containing huntingtin fragments into amyloid-like fibrils: implications for Huntington's disease pathology. Proc Natl Acad Sci USA 96:4604-4609.

Sieradzan KA, Mechan AO, Jones L, Wanker EE, Nukina N, Mann DM (1999) Huntington's disease intranuclear inclusions contain truncated, ubiquitinated huntingtin protein. Exp Neurol 156:92-99.

Simeoni S, Mancini MA, Stenoien DL, Marcelli M, Weigel NL, Zanisi M, Martini L, Poletti A (2000) Motoneuronal cell death is not correlated with aggregate formation of androgen receptors containing an elongated polyglutamine tract. Hum Mol Genet 9:133-144.

Stenoien DL, Cummings CJ, Adams HP, Mancini MG, Patel K DeMartino GN, Marcelli M, Weigel NL, Mancini MA (1999) Polyglutamine-expanded androgen receptors form aggregates that sequester heat shock proteins, proteasome components and SRC-1, and are suppressed by the HDJ-2 chaperone. Hum Mol Genet 8:731-741.

The Huntington's Disease Collaborative Research Group (1993) A novel gene containing a trinucleotide repeat that is expanded and unstable on Huntington's disease chromosomes. Cell 72:971-983.

Tobin AJ, Signer ER (2000) Huntington's disease: the challenge for cell biologists. Trends Cell Biol 10:531-536.

Turmaine M, Raza A, Mahal A, Mangiarini L, Bates GP, Davies SW (2000) Nonapoptotic neurodegeneration in a transgenic mouse model of Huntington's disease. Proc Natl Acad Sci USA 97:8093-8097.

Vallano ML (1990) Developmental regulation of type II calcium/ calmodulin-dependent kinase isoforms in rat cerebellum. J Neurobiol 21:1262-1273.

Vonsattel JP, Myers RH, Stevens TJ, Ferrante RJ, Bird ED, Richardson EP Jr (1985) Neuropathological classification of Huntington's disease. J Neuropathol Exp Neurol 44:559-577.

Waelter S, Boeddrich A, Lurz R, Scherzinger E, Lueder G, Lehrach H, Wanker EE (2001) Accumulation of mutant huntingtin fragments in aggresome-like inclusion bodies as a result of insufficient protein degradation. Mol Biol Cell 12:1393-1407.

Wexler NS, Young AB, Tanzi RE, Travers H, Starosta-Rubinstein S, Penney JB, Snodgrass SR, Shoulson I, Gomez F, Ramos Arroyo MA, et al. (1987) Homozygotes for Huntington's disease. Nature 326:194-197.

Wyttenbach A, Carmichael J, Swartz J, Furlong RA, Narain Y, Rankin J, Rubinsztein DC (2000) Effects of heat shock, heat shock protein 40 (HDJ-2), and proteasome inhibition on protein aggregation in cellular models of Huntington's disease. Proc Natl Acad Sci USA 97:2898-2903.

Yamamoto A, Lucas JJ, Hen R (2000) Reversal of neuropathology and motor dysfunction in a conditional model of Huntington's disease. Cell 101:57-66. 